\title{
Role of Plant Extracts in Treatment of Cerebral Ischemia
}

\author{
Seyyed Hossein $\mathrm{H}^{1 *}$ and Seyyedeh Zeinab $\mathrm{K}^{2}$ \\ ${ }^{1}$ Young Researchers and Elite Club, Islamic Azad University, Iran \\ ${ }^{2}$ Department of Biology, Yasouj University, Iran
}

Review Article

Volume 2 Issue 1

Received Date: January 21, 2018

Published Date: February 01, 2018

*Corresponding author: Hassanpour SH, Young Researchers and Elite Club, Yasooj

Branch, Islamic Azad University, Yasooj, Iran, 7591181963, Tel: +98 9171452844, Fax: +98 7433372379 ; E-mail:

Dr.hossein1366@yahoo.com

\begin{abstract}
Stroke is a major cause of disability and the third leading cause of mortality in human. In recent decades, the incidence of stroke has significantly increased especially in developing countries. Approximately $20 \%$ of patients die within one month after the stroke. Moreover, patients who live more than six months are dependent others for their daily work. They have complications such as paralysis of a body part, impairment of memory, thinking, talking and moving. Due to the complex pathological process of ischemia, using a single agent in the treatment of ischemia does not seem ideal. Thus, studies for finding compounds and effective methods are growing. In recent years, attention to medicinal plants as a potential source in treatment of ischemia-reperfusion has increased. Here, association between medicinal plants with reduction of cerebral ischemia was reviewed. At the end, it was determined potential of medicinal plants in abrogation of cerebral ischemia through several different pathways. Thus, they can be a new source for production of medications against cerebral ischemia.
\end{abstract}

Keywords: Stroke; Ischemia; Medicinal Plants; Cerebral Ischemia

\section{Introduction}

Stroke is the third leading cause of mortality and disability in industrialized countries besides patients with stroke has commonly complications such as paralysis of a body part and problems in function of memory, thinking, talking and moving. It has been reported that 15 and $85 \%$ of strokes is due to hemorrhage and ischemic, respectively. Factors such as thrombosis and embolism and systemic blood reduction have pivotal role in induction of ischemia [1]. Cerebral ischemia leads to neurological disorders such as problems in movement and speech as well as neuropsychiatric defects such as cognitive dysfunction and apraxia, learning and spatial memory impairment [2]. High blood pressure, diabetes, smoking, alcohol drinking, dyslipidemia, hypercholesterolemia are main factors that increase risk of stroke [3]. Brain needs to $25 \%$ of cardiac output for its metabolic activities and therefore any reduction in cerebral blood flow may lead to ischemia and neurodegenerative disorders [4]. Production of free radicals and reactive species are main event during cerebral ischemia that results in damage to lipids, proteins and deoxyribonucleic acid and ultimately neuronal death through its high reactivity. They have also a pivotal role in breaking of blood-brain barrier and brain edema [5]. In fact, reducing temporary or continual blood flow in brain results in reduction or lack of glucose transport and oxygen required to provide cellular homeostasis. At this 
stage, processes such as cell toxicity induced by acidosis, disturbance of ions balance, oxidative stress, lipid peroxidation, inflammation and lead to cell death. In addition, apoptosis induction through either intrinsic or extrinsic pathway exacerbates brain damage (Figure 1). In the next stage, reperfusion, lead to impairment in mitochondrial function, and releasing of glutamate and inflammatory mediators, production of reactive oxygen species and lipid peroxidation [6,7]. In spite of thrombolytic with recombinant tissue plasminogen activator, which is effective within $3 \mathrm{hr}$ after onset of ischemic symptoms, there is not prominent treatment in order to reduction of ischemia. In addition, given that occurrence of apoptosis in late phase of ischemia with low speed, the use of apoptosis inhibitor of is considered as next step treatment $[1,8]$. In fact, due to the complex pathological process, using a single agent in the treatment of ischemia does not seem ideal and therefore studies for finding effective compounds is expanding [6]. Moreover, in recent years it has been increased more attention to medicinal plants and their active ingredients as a potential source in the treatment of ischemia [9]. Medicinal herbs due to its low cost, simple availability, long-term history in treatment as well as fewer side effects have attracted more attention [10]. In previous studies, it have been reported the neuroprotective effects of medicinal plants in different parts of the world and given that a number of studies were done on the effects of medicinal plants and their active constituents on cerebral ischemia and understanding of its mechanism. Therefore, in this study, the relationship between the protective effects of extracts prepared from herbs with ischemic treatment was reviewed.

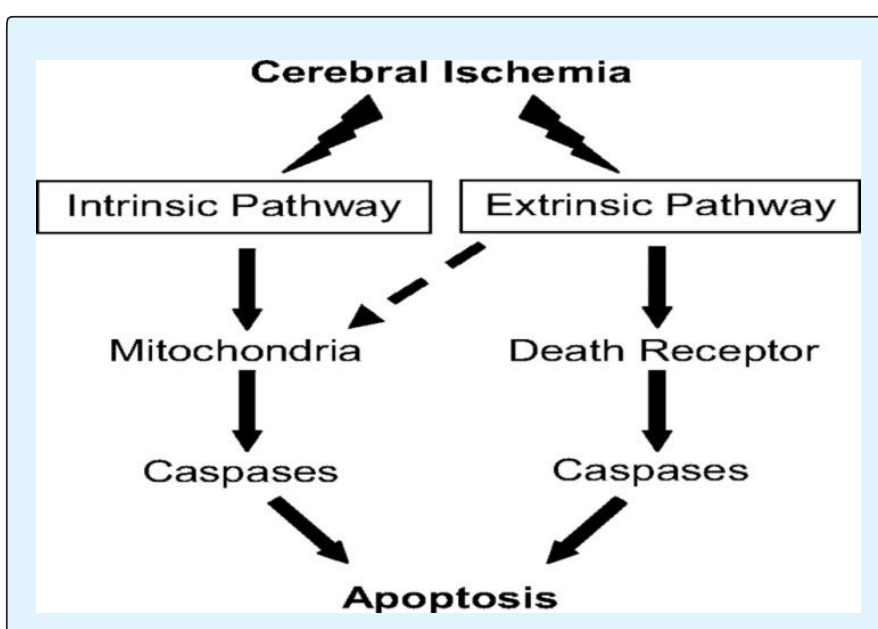

Figure 1: Induction of apoptosis during cerebral ischemia [7].

\section{Review Method}

In this review, we collected paper related to role of plant extracts in treatment of cerebral ischemia from 2000 to 2017 using keywords such as plant extract and cerebral ischemia, animal model of cerebral ischemia and herbs, herbs and extract and stroke in databases include web of science, PubMed and Scopus since. Then, the paper were read and summarized as shown in Table 1 .

\begin{tabular}{|c|c|c|c|c|}
\hline Plant & Extract & Animal model & Finding(s) & Reference \\
\hline \multirow{3}{*}{ Vitis vinifera } & Ethanolic & \begin{tabular}{|c|} 
Rats with permanent \\
hypoperfusion/ischemia (2CCAO \\
model)
\end{tabular} & $\begin{array}{c}\text { Recovery of passive avoidance } \\
\text { memory, increase of } \\
\text { hippocampal LTP }\end{array}$ & [11] \\
\hline & Ethanolic & \begin{tabular}{|c|} 
Rats with permanent \\
hypoperfusion/ischemia (2CCAO \\
model)
\end{tabular} & $\begin{array}{l}\text { Improvement of memory } \\
\text { dysfunction }\end{array}$ & [12] \\
\hline & Ethanolic & $\begin{array}{c}\text { Rats with carotid arteries } \\
\text { occlusion (2VO model) }\end{array}$ & Reduction of MDA in striatum & [13] \\
\hline \multirow{4}{*}{ Punica granatum } & $\begin{array}{c}\text { standardized extract to } \\
40 \% \text { ellagic acid }\end{array}$ & $\begin{array}{l}\text { Rats with cerebral } \\
\text { ischemia/reperfusion }\end{array}$ & $\begin{array}{c}\text { To have anti-oxidant, anti- } \\
\text { inflammatory and anti-apoptotic } \\
\text { effects }\end{array}$ & {$[4]$} \\
\hline & Ethanolic & \begin{tabular}{|c|} 
Rats with permanent \\
hypoperfusion/ischemia (2CCAO \\
model)
\end{tabular} & $\begin{array}{l}\text { Improvement of active and } \\
\text { passive avoidance memories }\end{array}$ & {$[14]$} \\
\hline & Ethanolic & $\begin{array}{c}\text { Rats with permanent } \\
\text { hypoperfusion/ischemia (2CCAO } \\
\text { model) }\end{array}$ & $\begin{array}{l}\text { Abrogation of motor and cognitive } \\
\text { deficits }\end{array}$ & [15] \\
\hline & Hydro-alcoholic & \begin{tabular}{|c|} 
Rats with permanent \\
hypoperfusion/ischemia (2CCAO \\
model)
\end{tabular} & $\begin{array}{l}\text { Improvement of memory } \\
\text { function }\end{array}$ & [16] \\
\hline
\end{tabular}




\begin{tabular}{|c|c|c|c|c|}
\hline Apocynum venetum & Hydro-alcoholic & $\begin{array}{l}\text { Cerebral ischemia induced by } \\
\text { occlusion of middle cerebral } \\
\text { artery }\end{array}$ & \begin{tabular}{|c|} 
Enhancement of neurological \\
function, reduction of cerebral \\
nfarct area, morphological injury, \\
down regulation of MMP-9/-2
\end{tabular} & [17] \\
\hline \multirow[t]{2}{*}{ Olea europaea } & EFLA 943 & $\begin{array}{l}\text { Mongolian gerbils (rodent) with } \\
\text { transient global cerebral ischemia }\end{array}$ & $\begin{array}{c}\text { Reduction of oxidative stress and } \\
\text { neurological damage in } \\
\text { hippocampus }\end{array}$ & [18] \\
\hline & $\begin{array}{c}\text { Standardized extract } \\
\text { with oleuropein }\end{array}$ & $\begin{array}{l}\text { Rats with experimental focal } \\
\text { cerebral ischemia model }\end{array}$ & $\begin{array}{c}\text { To have neuroprotective effect, } \\
\text { improvement of lipid profile }\end{array}$ & [19] \\
\hline Nigella sativa & Aqueous & $\begin{array}{c}\text { Rats with global } \\
\text { ischemia/reperfusion }\end{array}$ & $\begin{array}{c}\text { Improvement of histopathological } \\
\text { damages in hippocampus }\end{array}$ & [20] \\
\hline $\begin{array}{l}\text { Rosa laevigata } \\
\text { Michx }\end{array}$ & Flavonoid-rich extract & $\begin{array}{l}\text { Rats with cerebral ischemia- } \\
\text { reperfusion (MCAO model) }\end{array}$ & $\begin{array}{c}\text { To have anti-apoptotic and anti- } \\
\text { inflammatory properties }\end{array}$ & [6] \\
\hline Zingiber officinale & Aqueous & $\begin{array}{l}\text { Rats with right middle cerebral } \\
\text { artery occlusion (MCAO model) }\end{array}$ & $\begin{array}{l}\text { Normalization of oxidative } \\
\text { condition and cognitive } \\
\text { dysfunction }\end{array}$ & [21] \\
\hline \multirow{2}{*}{ Crocus sativus } & Aqueous & $\begin{array}{l}\text { Rats with middle cerebral artery } \\
\text { occlusion }\end{array}$ & $\begin{array}{c}\text { To have potential antioxidant } \\
\text { effects }\end{array}$ & [22] \\
\hline & Hydro-alcoholic & $\begin{array}{c}\text { Rats with cerebral ischemia by } \\
\text { carotid artery ligation }\end{array}$ & $\begin{array}{c}\text { Recovery of spatial learning and } \\
\text { memory }\end{array}$ & [23] \\
\hline Boswellia serrata & Aqueous and ethanolic & \begin{tabular}{|c|} 
Rats with middle cerebral artery \\
occlusion-induced cerebral \\
ischemia-reperfusion injury
\end{tabular} & $\begin{array}{c}\text { To have antioxidant and anti- } \\
\text { apoptotic properties, reduction } \\
\text { of neurological deficit and brain } \\
\text { infarction }\end{array}$ & [24] \\
\hline Embelia ribes & Ethanolic & $\begin{array}{c}\text { Rats with middle cerebral artery } \\
\text { occlusion-induced focal cerebral } \\
\text { ischemia }\end{array}$ & $\begin{array}{l}\text { To have potential anti-oxidant } \\
\text { effect in in hippocampus and } \\
\text { frontal cortex }\end{array}$ & [25] \\
\hline $\begin{array}{l}\text { Rosmarinus } \\
\text { Officinalis }\end{array}$ & Hydro-alcoholic & $\begin{array}{l}\text { Rats with middle cerebral artery } \\
\text { occlusion }\end{array}$ & $\begin{array}{c}\text { Enhancement of neurologic } \\
\text { deficit, cerebral edema, blood- } \\
\text { brain barrier permeability }\end{array}$ & [26] \\
\hline Cyperus rotundus & Hydro-alcoholic & $\begin{array}{l}\text { Rats with global ischemic- } \\
\text { reperfusion injury }\end{array}$ & Jp regulation of $B c l-x 1$ expression & [27] \\
\hline Pistacia vera & Hydro-alcoholic & $\begin{array}{l}\text { Rat with four-vessel occlusion } \\
\text { model }\end{array}$ & $\begin{array}{c}\begin{array}{c}\text { To have potential antioxidant } \\
\text { property in brain }\end{array} \\
\end{array}$ & [28] \\
\hline Allium сера & Methanolic & Rats with global cerebral ischemia & \begin{tabular}{|} 
Reduction of cerebral infarct size \\
and mitochondrial TBARS, \\
improvement of short-term \\
memory and motor coordination
\end{tabular} & [29] \\
\hline $\begin{array}{c}\text { Wedelia } \\
\text { calendulacea }\end{array}$ & Methanolic & $\begin{array}{l}\text { Rats with global cerebral } \\
\text { ischemia }\end{array}$ & $\begin{array}{c}\text { Normalization of enzymatic } \\
\text { antioxidant defense and } \\
\text { histopathological changes } \\
\text { in brain }\end{array}$ & [30] \\
\hline
\end{tabular}

Table 1: Role of extract of herb in treatment of cerebral ischemia.

LTP: long-term potentiation; MDA: malondialdehyde; EFLA 943: a standardized olive leaf extract to 18-26\% of oleuropein; MMP: matrix metalloproteinase

\section{Plant Extract and their Role in Cerebral Ischemia Treatment}

Our study about role of ethanolic extract prepared from Vitis vinifera (grape) in treatment of cerebral ischemia showed that administration of this extract to male adult rats with permanent bilateral common carotid arteries occlusion results in enhancement of memory impairment and increment of hippocampal long-term potentiation. Given that grape is known as an antioxidant plant, probably this effects can be related to its antioxidant property [11]. In another our study on rats with permanent bilateral common carotid arteries occlusion, it 
has been revealed that use of exercise along with ethanolic extract of Vitis vinifera(grape) lead to improvement of memory dysfunction after determination of passive avoidance memory at the end of study [12]. We also showed that administration of ethanolic extract obtained from grape to rats with carotid arteries occlusion lead to improvement of oxidative condition in brain of rats by obvious reduction of lipid peroxidation using determination of malondialdehyde in striatum [13]. In a study, it was investigated effects of standardized pomegranate extract against cerebral ischemia/reperfusion-induced brain injury in rats and evaluated parameters related to oxidative stress and inflammation as well as apoptosis. At the end of study, it has been showed that it reduced levels of MDA and NO and normalized enzymes activity related to antioxidant defense include SOD (superoxide dismutase), GPX (glutathione peroxidase), and GRD (glutathione reductase). In addition, extract reduced levels of NF- $\kappa B$ p65, TNF- $\alpha$ and increased level of IL-10 in brain. It had also antiapoptotic effect by reduction of enzyme activity of caspase3. In final, standardized pomegranate extract leads to obvious increase of cerebral ATP [4]. According to our studies, ethanolic extract prepared from Punica granatum (pomegranate) enhances functions of active and passive avoidance memories and reduced motor and cognitive deficits after its treatment in rats with to permanent cerebral hypoperfusion/ischemia injury $[14,15]$. In another study, we confirmed that pomegranate is a useful plant in order to treatment of cerebral ischemia so that its hydro-alcoholic extract leads to obvious improvement of memory function in rats with permanent bilateral common carotid arteries occlusion [16]. In a study, cerebral ischemia was induced by occlusion of the middle cerebral artery for $90 \mathrm{~min}$ in rats and then animal were treated by hydro-alcoholic extract prepared by Apocynum venetum. At the end of study, tetrazolium and Evan's blue staining and transmission electron microscopy respectively evaluated cerebral infarct area, blood-brain barrier permeability and pathological changes on the ultra-structure of the bloodbrain barrier. In addition, it was determined the expression and activities of matrix metalloproteinase (MMP)-9/-2. The results showed that hydro-alcoholic extract prepared by Apocynum venetum had prominent effect in improvement of neurological function and reduction of cerebral infarct area along with normalization of morphological injury. In association with MMP-9/-2, it was revealed that extract leads to reduction of expression and activities MMP-9/-2 in brain. Thus this study suggests that Apocynum venetum is a promising herb to treat cerebral ischemia [17]. A research group was induced transient global cerebral ischemia in Mongolian gerbils and then they treated animals with standardized dry olive (Olea europaea) leaf extract. In order to determination of oxidative stress condition and neuronal damage in hippocampus, parameters such as levels of superoxide and nitric oxide and lipid peroxidation, superoxide dismutase activity were measured. At the end of study, they found that this extract leads to normalization of oxidative condition by reduction of superoxide and nitric oxide and lipid peroxidation and increase of superoxide dismutase activity. It also had obvious effect in abrogation of neuronal damage in CA1 region of hippocampus [18]. Moreover, it has been reported that standardized extract with oleuropein obtained from Olea europaea results in effects of promising protective against damage induced by cerebral ischemia due to reduction of infarct volume and edema in brain and increase of blood-brain barrier permeability. In addition, it reduced LDL/HDL ratio [19]. Evaluation of the neuroprotective effects of aqueous extract related to Nigella sativa on model of global ischemia/reperfusion in rats was confirmed that it has potential able to prevent ischemia/reperfusion in hippocampus tissue of brain. In fact, this study showed that its administration leads to prevention of intracellular edema of interneurons, reduction edematous astrocytes [20]. Study on effect of flavonoid-rich extract obtained from Rosa laevigata Michx againstcerebral ischemiareperfusion injury in Sprague-Dawley rats was showed that oral administration of extract antiapoptotic effects through up-regulation of expression of Bcl-2, downregulation of expressions of p53, Apaf1, Fas, FasL, Bax, Bid, cytochrome $\mathrm{C}$ and active Caspase-3, -9 and -8 and reduction of DNA fragmentation. In addition, extract has anti-inflammatory effect through reduction of expressions of NF- $\kappa B$, iNOS, MMP-9, COX-2, TNF- $\alpha$, IL-1 $\beta$, IL-4, IL-6, and down-regulation of levels of p-JNK, p-ERK and p-p38 in MAPK pathways. These events resulted in improvement of survival rate and prevention of I/R-induced disability and histological injury [6]. Treatment of rats with cerebral ischemia induced by right middle cerebral artery occlusion with aqueous extract prepared from ginger (Zingiber officinale) resulted in enhancement of cognitive dysfunction as well as normalization of oxidative condition through increase of enzymes activity of catalase and glutathione peroxidase, superoxide dismutase in cerebral cortex and hippocampus [21]. Study on role of saffron against damages induced by cerebral ischemia was confirmed that aqueous extract prepared from saffron (Crocus sativus) has antioxidant effect by increase of enzymes activity of glutathione peroxidase, glutathione reductase, glutathione S-transferase, superoxide dismutase, catalase and $\mathrm{Na}^{+}, \mathrm{K}^{+}$-ATPase and level of glutathione as well as reduction of malondialdehyde in rats with middle cerebral artery occlusion [22]. In another study, it has been showed that treatment with hydroalcoholic extract of saffron improves spatial learning and memory in rats with cerebral ischemia through carotid 
artery ligation Boswellia serrata can be consider as a useful plant to treat cerebral ischemia due to oral administration of aqueous and ethanolic extracts obtained from Boswellia serrata lead to reduction of neurological deficit and brain infarction [23]. In addition, this extract has antioxidant and anti-apoptotic effect through reduction of lipid peroxidation and increase of glutathione level and superoxide dismutase activity as well as reduction of caspase-3 activity, down regulation of bax and up regulation of bcl-2 in rats with middle cerebral artery occlusion-induced cerebral ischemia-reperfusion injury [24]. In a study effect of ethanolic extract prepared from Embelia. Ribes Burm on middle cerebral artery occlusion (MCAO)-induced focal cerebral ischemia in rats was investigated. The results showed that administration of extract has antioxidant effect because leads to normalization of reduced glutathione and thiobarbituric acid reactive substance levels and activity of glutathione peroxidase, glutathione reductase and glutathione- $S$ transferase enzymes in hippocampus and frontal cortex and reduction of lactate dehydrogenase in serum. In addition extract increased grip strength activity in hippocampus and frontal cortex at the end of study. Given that, ethanolic extract prepared from Embelia. ribes Burm had antioxidant effect, thus it can be a promising candidate to treat cerebral ischemia [25]. Experiment on antiischemic effect of Rosmarinus officinalis hydro-alcoholic extract was confirmed improvement of neurologic deficit, cerebral edema, blood-brain barrier permeability in rats with cerebral ischemia after treatment [26]. Given that, increase of Bcl-x1 expression resulted from treatment with hydro-alcoholic extract of Cyprus rotundus in rats with global ischemic-reperfusion injury, therefore this extract has anti-apoptotic effect and is a promising herbs for reduction damages related to cerebral ischemia [27]. It has been reported that hydro-alcoholic extract of Pistacia Vera abrogated injuries related to cerebral ischemia in rats with four-vessel occlusion model. In fact, in this study showed that administration of hydro-alcoholic extract of Pistacia vera reduced level of malondialdehyde and increased antioxidant power using evaluation of thiobarbituric acid and ferric reducing-antioxidant power tests I brain of rats [28]. Given that methanolic extract prepared from Allium cepa results in reduction of cerebral infarct size and mitochondrial TBARS as well as improvement of shortterm memory and motor coordination in rats with global cerebral ischemia induced by bilateral carotid artery occlusion, therefore it has potential effects against cerebral ischemia [29]. Study on rats with global cerebral ischemia was revealed that methanolic extract of Wedelia calendulacea has potential anti-ischemic effect due to reduction of oxidative stress through reduction of malondialdehyde and hydrogen peroxide levels and increase of activity of glutathione peroxidase, glutathione reductase and glutathione-s-transferase as well as normalization of histopathological changes in brain [30].

\section{Conclusion}

In this review, we found that extract prepared from herbs could reduce volume of brain lesions, neuronal damage and movement disorders by abrogation of oxidative stress, expression of inflammatory mediators and inhibition of apoptosis and DNA fragmentation. In fact, this study showed positive effects of a number of medicinal plants in order to mitigate the deleterious effects of ischemia. This is a very important point that most studies have been done on animal models and have not been done studies on the protective effect of herbs against cerebral ischemia in humans. According to plants compounds metabolized under enzymatic processes in liver and may be altered their structure and therefore their effects. Thus, it is recommended that should do clinical studies besides pre-clinical studies. During ischemia and reperfusion, occurrence of cellular and molecular processes causes damages in neural and non-neural cells and also brain's capillaries. These events induce cytotoxicity, oxidative stress, lipid peroxidation, ions imbalance, the releasing of inflammatory mediators and impairment of mitochondrial function. Due to the complex pathological events during ischemia-reperfusion process, use of a single agent in the treatment of ischemia does not seem ideal. In general, review on conducted studies in association with effects of plants in treatment of ischemia confirms that plants have pivotal role in reduction of damages induced by cerebral ischemia through different pathways. Therefore, the development of protective factors from herbs can be a promising way in the treatment of cerebral ischemic. Finally, we suggest that perform future studies in order to detection of protective effects of plants against cerebral ischemia in the human models. In addition, it should be consider their side effect, toxicity, and ability for crossing from blood-brain barrier.

\section{Declarations}

Acknowledgements: Us acknowledgements and gratefulness at the beginning and at last is to god who gave us the gift of the mind. The authors thank Young Researchers and Elite Club, Yasooj Branch, Islamic Azad University due to cooperation in this study.

Conflict of interest statement: The authors declare that there is no conflict of interest regarding this study.

Financial support and sponsorship: This study was supported by the authors named in this article alone.

Contribution of Authors: This work was done by the authors named in this article and all liabilities pertaining 
to claims relating to the content of this article was borne by the authors named in this article.

Ethical approval: This research does not contain any studies with human participants or animals and was performed by the authors alone.

\section{References}

1. Lakhan SE, Kirchgessner A, Hofer M (2009) Inflammatory mechanisms in ischemic stroke: therapeutic approaches. J Transl Med 7(1): 97.

2. Hosseinzadeh H, Hosseini A, Nassiri-Asl M, Sadeghnia HR (2007) Effect of Salvia leriifolia Benth. root extracts on ischemia-reperfusion in rat skeletal muscle. BMC Complement Altern Med 7(1): 23.

3. Bora KS, Arora S, Shri R (2011) Role of Ocimum basilicum L. in prevention of ischemia and reperfusion-induced cerebral damage, and motor dysfunctions in mice brain. J Ethnopharmacol 137(3): 1360-1365.

4. Ahmed MA, El Morsy EM, Ahmed AA (2014) Pomegranate extract protects against cerebral ischemia/reperfusion injury and preserves brain DNA integrity in rats. Life Sci 110(2): 61-69.

5. White BC, Sullivan JM, DeGracia DJ, O'Neil BJ, Neumar RW, et al. (2000) Brain ischemia and reperfusion: molecular mechanisms of neuronal injury. J Neurol Sci 179(1-2): 1-33.

6. Zhang S, Qi Y, Xu Y, Han X, Peng J, et al. (2013) Protective effect of flavonoid-rich extract from Rosa laevigata Michx on cerebral ischemia-reperfusion injury through suppression of apoptosis and inflammation. Neurochem Int 63(5): 522-532.

7. Broughton BR, Reutens DC, Sobey CG (2009) Apoptotic mechanisms after cerebral ischemia. Stroke 40(5): e331-e339.

8. Rami A, Langhagen A, Steiger S (2008) Focal cerebral ischemia induces upregulation of Beclin 1 and autophagy-like cell death. Neurobiol Dis 29(1): 132141.

9. Raouf Sarshoori J, Asadi MH, Mohammadi MT (2014) Effect of olive oil on the cerebral reperfusion following ischemia injuries in rat. J Birjand Univ Med Sci 21(1): 56-67.

10. Elango C, Jayachandaran KS, Devaraj SN (2009) Hawthorn extract reduces infarct volume and improves neurological score by reducing oxidative stress in rat brain following middle cerebral artery occlusion. Int J Dev Neurosci 27(8): 799-803.

11. Sarkaki A, Rafieirad M, Hossini SE, Farbood Y, Motamedi F, et al. (2013) Improvement in memory and brain long-term potentiation deficits due to permanent hypoperfusion/ischemia by grape seed extract in rats. Iran J Basic Med Sci 16(9): 1004-1010.

12. Sarkaki A, Rafieirad M, Hossini SE, Farbood Y, Mansouri SMT, et al. (2012) Cognitive deficiency induced by cerebral hypoperfusion/ischemia improves by exercise and grape seed extract. Health Med 6(4): 1097-1104.

13. Rafiei RM, Sarkaki A, Hoseini E, Farbood Y, Mansouri S, et al. (2011) The effect of grape seed extract on lipid peroxidation duo to ischemia/hypoperfusion in male rat striatum. JAB 3(4): 37-44.

14. Sarkaki A, Rezaiei M, Naseri MG, Rad MR (2013) Improving active and passive avoidance memories deficits due to permanent cerebral ischemia by pomegranate seed extract in female rats. Malays J Med Sci 20(2): 25-34.

15. Hajipour S, Sarkaki A, Mohammad S, Mansouri T, Pilevarian A, et al. (2014) Motor and cognitive deficits due to permanent cerebral hypoperfusion/ischemia improve by pomegranate seed extract in rats. Pak J Biol Sci 17(8): 991-998.

16. Sarkaki A, Hajipour S, Mansouri MT, Pilevarian A, Rad MR (2013) Pomegranate seed hydroalcoholic extract improves memory deficit due to permanent cerebral hypoperfusion/ischemia in male rats. Health Med 7(3): 863-871.

17. Xiang J, Lan R, Tang YP, Chen YP, Cai DF (2012) Apocynum venetum leaf extract attenuates disruption of the blood-brain barrier and upregulation of matrix metalloproteinase-9/-2 in a rat model of cerebral ischemia-reperfusion injury. Neurochem Res 37(8): 1820-1828.

18. Dekanski D, Selaković V, Piperski V, Radulović Z, Korenić A, et al. (2011) Protective effect of olive leaf extract on hippocampal injury induced by transient global cerebral ischemia and reperfusion in Mongolian gerbils. Phytomedicine 18(13): 1137-1143.

19. Mohagheghi F, Bigdeli MR, Rasoulian B, Hashemi P, Pour MR (2011) The neuroprotective effect of olive leaf extract is related to improved blood-brain barrier 


\section{International Journal of Pharmacognosy and Chinese Medicine}

permeability and brain edema in rat with experimental focal cerebral ischemia. Phytomedicine 18(2): $170-175$.

20. Hobbenaghi R, Javanbakht J, Sadeghzadeh S, Kheradmand D, Abdi F, et al. (2014) Neuroprotective effects of Nigella sativa extract on cell death in hippocampal neurons following experimental global cerebral ischemia-reperfusion injury in rats. J Neurol Sci 337(1-2): 74-79.

21. Jittiwat J, Wattanathorn J (2012) Ginger pharmacopuncture improves cognitive impairment and oxidative stress following cerebral ischemia. J Acupunct Meridian Stud 5(6): 295-300.

22. Saleem S, Ahmad M, Ahmad AS, Yousuf S, Ansari MA, et al. (2006) Effect of Saffron (Crocus sativus) on neurobehavioral and neurochemical changes in cerebral ischemia in rats. J Med Food 9(2): 246-253.

23. Hosseinzadeh H, Sadeghnia HR, Ghaeni FA, Motamedshariaty VS, Mohajeri SA (2012) Effects of saffron (Crocus sativus L.) and its active constituent, crocin, on recognition and spatial memory after chronic cerebral hypoperfusion in rats. Phytother Res 26(3): 381-386.

24. Forouzanfar F, Hosseinzadeh H, Ebrahimzadeh Bideskan A, Sadeghnia HR (2016) Aqueous and Ethanolic Extracts of Boswellia serrata Protect Against Focal Cerebral Ischemia and Reperfusion Injury in Rats. Phytother Res 30(12): 1954-1967.
25. Nazam Ansari M, Bhandari U, Islam F, Tripathi C (2008) Evaluation of antioxidant and neuroprotective effect of ethanolic extract of Embelia ribes Burm in focal cerebral ischemia/reperfusion-induced oxidative stress in rats. Fundam Clin Pharmacol 22(3): 305-314.

26. Rahnema M, Seyedemadi P, Bigdeli MR, Oryan S, Rafati $\mathrm{H}$ (2016) The neuroprotective effect of rosemary (Rosmarinus Officinalis L.) hydroalcoholic extract on cerebral ischemic tolerance in experimental stroke. Iran J Pharm Res 15(4): 875-883.

27. Farahani K, Hashemi M (2016) Investigating the Effect of Hydroalcoholic Extract of Cyperus rotundus L. on the Expression of Bcl-x1 Antiapoptotic Gene in Rats' Hippocampus Tissue Following Global IschemicReperfusion Injury. Acta Medica Iranica 54(4): 256260.

28. Mansouri SMT, Naghizadeh B, Hosseinzadeh H (2005) The effect of Pistacia vera $L$. gum extract on oxidative damage during experimental cerebral ischemiareperfusion in rats. Iranian Biomedical Journal 9(4): 181-185.

29. Shri R, Bora KS (2008) Neuroprotective effect of methanolic extracts of Allium cepa on ischemia and reperfusion-induced cerebral injury. Fitoterapia 79(2): 86-96.

30. Prakash T, Kotresha D, Nedendla RR (2011) Neuroprotective activity of Wedelia calendulacea on cerebral ischemia/reperfusion induced oxidative stress in rats. Indian J Pharmacol 43(6): 676-682. 